\title{
PENGEMBANGAN VARIAN BATIK IKAT CELUP DUSUN HENDROSALAM MELALUI OLSHOP DI ERA PANDEMI
}

\author{
Dewi Suprobowati ${ }^{1}$, Mulus Sugiharto ${ }^{2}$, Miskan $^{3}$ \\ Program Studi Administrasi Publik, FISIP, Universitas Wijaya Putra \\ dewisuprobowati@uwp.ac.id
}

\begin{abstract}
Abstrak
Pemanfaatan zat pewarna alam untuk tekstil menjadi salah satu alternatif pengganti zat pewarna berbahan kimia. Adapun zat pewarna alami diperoleh dari alam yang berasal dari hewan(lac dyes) atau tumbuhan seperti akar,kayu,batang, daun serta kulit dan bunga,getah bunga (lac dye). Contoh warna alami Tegeran,Mahoni,kelengkeng,kluwih. Ada dua teknik membuat batik jumputan pertama teknik ikat dan kedua teknik jahitan.Ikat celup menghias kain dengan cara diikat atau dijumput sedikit, dengan tali atau karet, dijelujur, dilipat sampai kedap air, lalu dicelup dengan pewarna batik. Proses pembuatan batik ikat celup kainnya diikat atau dijahit dan dikerut menggunakan tali. Seperti yang dilakukan oleh Perajin Batik Assalam RYY Dusun Hendrosalam RT 02 RW 04 Gresik.

Permasalahan Mitra aspek produksi, produk yang dihasilkan masih sederhana, desainnya terbatas. Solusi yang ditawarkan diberikan Pelatihan Varian batik ikat,Syaal,Jilbab,Masker,baju,tempat tisu.dll.Aspek manajemen permasalahannya cara pemasaran konvensional,serta kurang tertib administrasi. Solusi yang ditawarkan diberikan pelatihan pemasaran Via online (whatsapp,LINE, Instagram) dll, Pelatihan Administrasi keuangan menggunakan (MS Excell).Melalui pelatihan dan pendampingan diharapkan kelompok tersebut menjadi mandiri dan bisa menghasilkan karya batik ikat celup yang bagus, serta bisa dipasarkan dalam jangkauan yang lebih luas.
\end{abstract}

Kata kunci : Batik,Varian Produk, ikat celup

\section{PENDAHULUAN}

Indonesia adalah Negara yang terkenal dengan batiknya.Batik sendiri juga sudah ditetapkan oleh UNESCO sebagai warisan budaya asli dari Indonesia.Indonesia memiliki beragam kearifan lokal.Salah satu kearifan lokal lokal adalah produk tradisional batik.Seperti Batik Ikad Celup sebagai kain batik jumputan.Ikat celup berasal dari kosakata bahasa Inggris,tie-dye yang memiliki pengertian menghias kain dengan cara di ikat diikat/dijumput sedikit dengan tali/kaert,dijelujur,dilipatsampai kedap air,lalu dicelup dengan pewarna batik.Pada pembuatan batik inikainnya didikat /dijahit dan dikerut dengan menggunakan tali.

Ada dua teknik membuat batik jumputan, pertama teknik ikat, dan ke dua teknik jahitan. Teknik ikatan adalah bagian yang diikat kencang itu pada saat dicelup tidak terkena warna,setelah ikatannya dilepas akan terbentuk gambarnya.Teknik jahitan adalah kain diberi pola terlebih dahulu kemudian dijahit menggunakan tusuk jelujur pada garis warnanya menggunakan benang, lalu benang ditarik kuat sehingga kain berkerut serapat mungkin. Pada waktu dicelup benang yang rapat akan menghalangi warna masuk ke kain. Benang yang

Ekonomi, Sosial, dan Budaya 
dipakai sebaiknya benang tebal dan kuat seperti benang plastik / sintesis, benang jins, atau benang sepatu. Hasil jumputan teknik jahitan berupa titiktitik yang agak menyambung serta membentuk gambar.

\section{Mitra batik Asalam RYY Dusun}

Hendrosalam RT 02, RW 04 produk yang ada masih sangat sederhana/seadanya masih berupa kain batik saja.

Permasalahan mitra dari sisi produksi Produk yang dihasilkan masih sangat sederhana/desainnya terbatas. Dari sisi Manajemen; 1) Pemasaran masih sederhana secara konvensional,sehingga pasar masih terbatas 2) Belum adanya Administrasi Keuangan, pembukuan secara kusus untuk keuangan, baik pemasukan maupun pengeluaran.

Solusi yang ditawarkan dari sisi produksi Memberikan pelatihan varian produk batik pewarna alami. Membuat produkSyaal,Jilbab,mukena,masker,baju,tempat tisue. Dari sisi manajemen adalah 1) Pelatihan kemampuan pemasaran melalui Olshop Online (Whatsapp, LINE, Instagram). 2) peningkatan kemampuan mitra dalam menggunakan pembukuan administrasi keuangan secara sederhana dan rapi.

Pengembangan masyarakat (Community development) terdiri dari dua konsep, yaitu "Pengembangan" dan "masyarakat". pengembangan merupakan usaha bersama serta terencana untuk meningkatkan kualitas kehidupan manusia.Konsep dari komunitas adalah sekelompok orang dengan identitas bersama. Oleh karena itu, pengembangan masyarakat bergantung pada interaksi antara manusia dan aksi bersama daripada kegiatan individu apa yang beberapa ahli sosiologi menyebutnya dengan lembaga kolektif. Bidang-bidang pembangunan biasanya meliputi beberapa sektor yaitu : ekonomi, pendidikan, kesehatan dan sosial budaya.

Masyarakat dapat diartikan dalam dua konsep, yaitu : 1) masyarakat sebagai sebuah "tempat bersama”, yakni sebuah wilayah yang geografi yang sama. Sebagai contoh, sebuah rt perumahan di daerah perkotaan atau sebuah kampung di wilayah pedesaan.

2) Masyarakat sebagai "kepentingan bersama”, yakni kesamaan kepentingan berdasarkan kebudayaan dan identitas.Sebagai contoh, kepentingan bersama pada masyarakat etnis minoritas atau kepentingan bersama-sama berdasarkan identifikasi kebutuhan tertentu seperti halnya pada kasus para orang tua yang memiliki anak dengan kebutuhan kusus.

Hakikat dan tujuan pengembangan masyarakat untuk meningkatkan kesejahteraan manusia atau masyarakat. Hakikat dari pengembangan masyarakat adalah apa yang dirasakan oleh masyarakat itu sendiri, bukan apa yang dituliskan dalam angka atau teori. Dalam hal ini, ketika ditemukan data dalam bentuk angka tentang keadaan suatu masyarakat atau sebuah teori maka harus dikompromikan atau dicocokan dengan kondisi riil masyarakat karena sering kali yang terjadi adalah theory is not a reality.

Pengembangn masyarakat sebagai suatu proses bergerak dari satu tahap ke tahap yang lain, Ekonomi, Sosial, dan Budaya 
sebuah metode untuk menciptakan tujuan, sebuah prosedur program dan sebagai sebuah gerakan menyapu orang dalam emosi dan keyakinan.

Tujuan : 1) Menimbulkan rasa percaya kepada diri sendiri. 2) Menimbulkan rasa bangga, semangat, dan gairah kerja. 3) Meningkatkan dinamika untuk membangun. 4) Meningkatkan kesejahteraan msyarakat

Dalam mencapai tujuan pengembangan masyarakat harus dilakukan secara holistik atau dengan multidisipliner untuk meningkatkan derajat kesehatan masyarakat. Selain itu perlu di ingat bahwa manusia bersifat dinamis. (https:/luluhatta.Wordpress.com/2014/13/pengemb angan. Pengembangan masyarakat)

Pengembangan masyarakat lebih ditekankan pada upaya pemenuhan kebutuhan oleh masyarakat sendiri atau Pengembangan keswadayan masyarakat. Sasaran pengembangan masyarakat adalah pengembangan kapasitas masyarakat serta peningkatan kesejahteraan masyarakat dengan upaya pemberdayaan (empowerment) masyarakat agar mereka dapat melakukan transformasi ekonomi, teknologi dan sosial budaya.Berkaitan dengan hal tersebut diharapkan masyarakat dapat memanfaatkan keilmuan yang telah diberikan sesuai dengan bidang keahlian yang diinginkan.

Manfaat program mengikuti PKM CSR bagi mitra adalah menambahkan pengetahuan dan wawasan untuk pengembangan kesejahteraan masyarakat sesuai dengan bidang keahlian mitra serta memperluas jangkauan pemasaran.

\section{METODE PENGABDIAN}

Waktu serta Tempat Pengabdian

Waktu untuk pelaksanaan pada bulan Mei s/d desember 2020. Tempat pada RT 02,RW 04 Kecamatan menganti kabupaten Gresik.

Metode serta Rancangan Pengabdian yaitu Pelatihan dan pendampingan.

Tahapan Awal

Melalukan survey (analisis situasi mitra dari sisi produksi dan Manajemen) sampai menemukan kebutuhan pelatihannya

Tahapan Pelaksanaan

Pelatihan Pewarnaan varian produk (20 Mei 2020)

Pelatihan untuk pemasaran produk bisa melalui olshop (Whatsapp, LINE, Instagram (tanggal 27 Mei 2020)

Pelatihan untuk pencatatan administrasi keuangan atau pembukuan sederhana (tanggal 30 Mei 2020)

Tahapan monitoring dan Evaluasi

Pelaksanaan monitoring dan evaluasi dalam Pengabdian Masyarakat ini : antara bulan Mei - Desember 2020. 


\section{HASIL DAN PEMBAHASAN}

Hasil Pengabdian masyarakat ini Nampak dalam gambar berikut ini :

Gambar 1 Produk Batik

Gambar 1 Syal
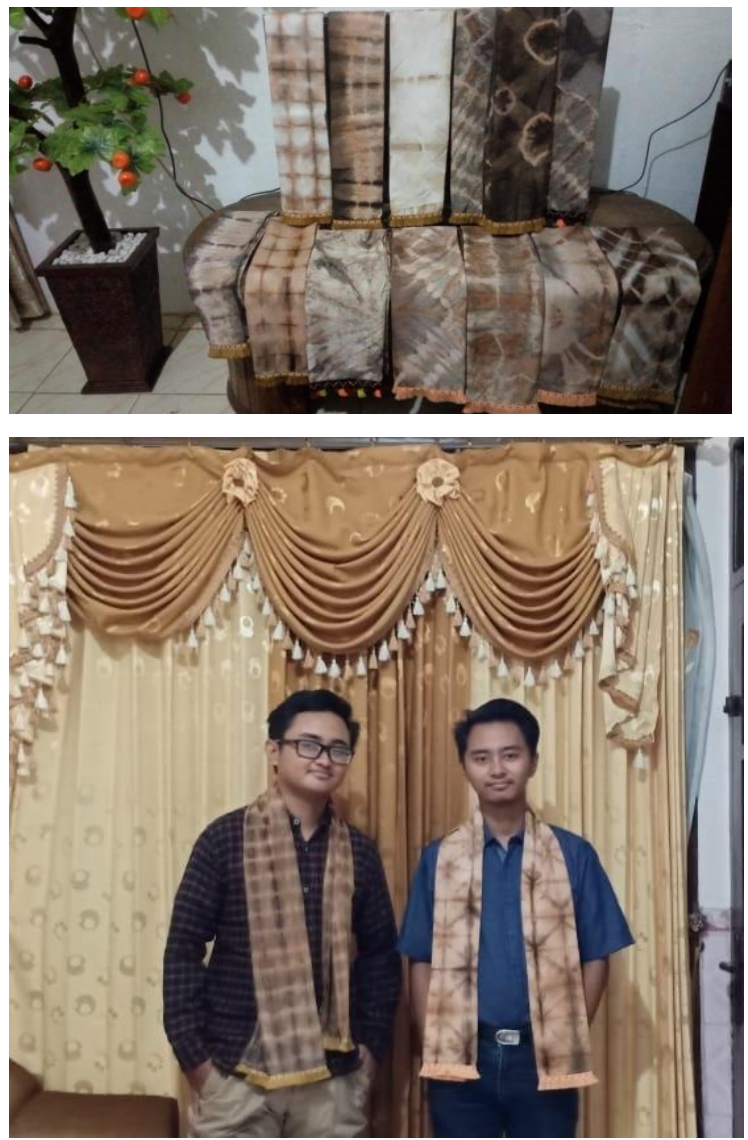

Gambar 2 Produk Sapu Tangan

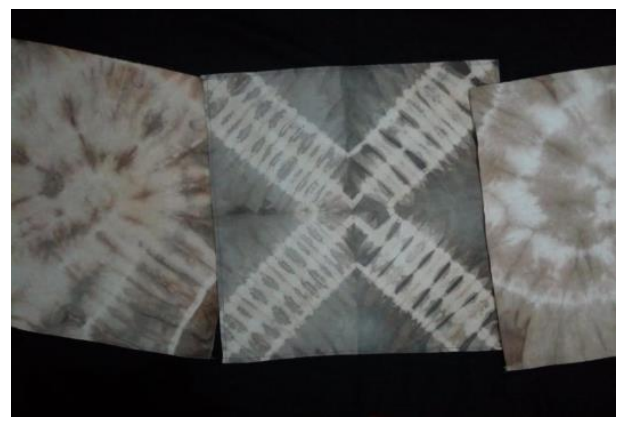

Gambar 3 Produk Tas Wanita

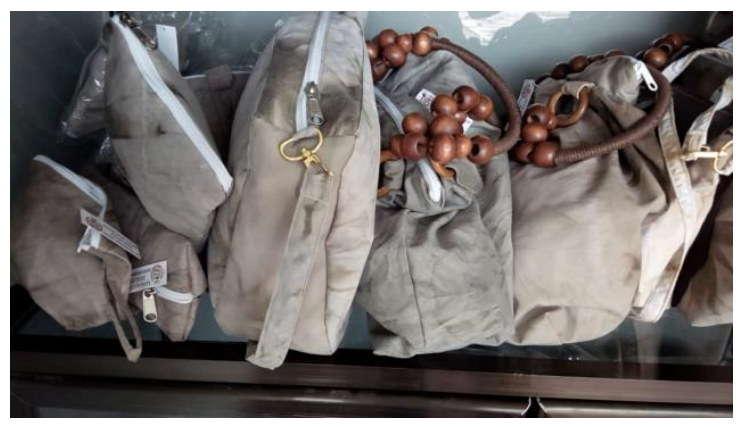

Gambar 4 Produk Masker

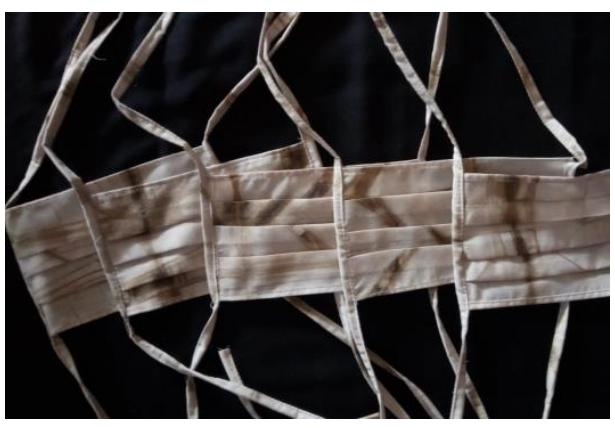

Gambar 5 Produk Outer Batik

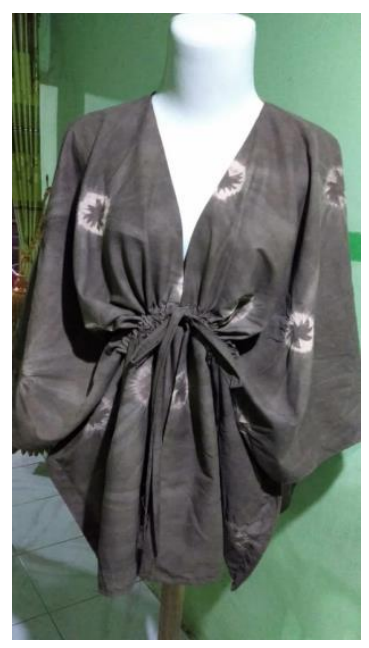

Gambar 6 Produk Baju \& Mukenah 


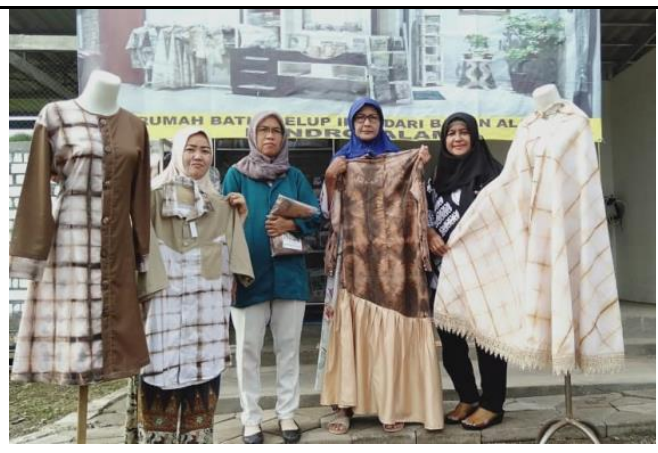

Gambar 7 Produk Jilbab

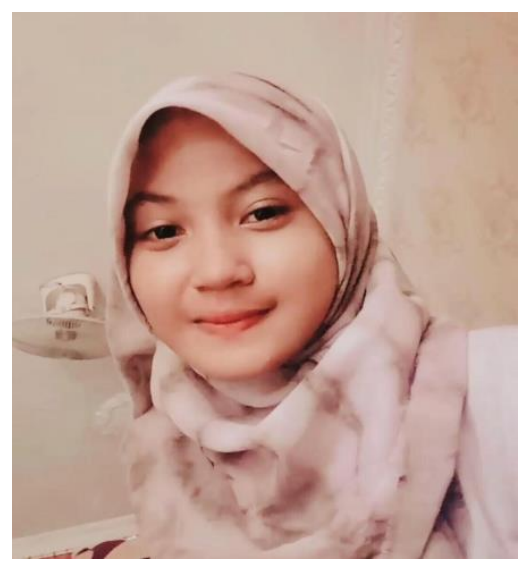

Gambar 8 Produk Kain Batik

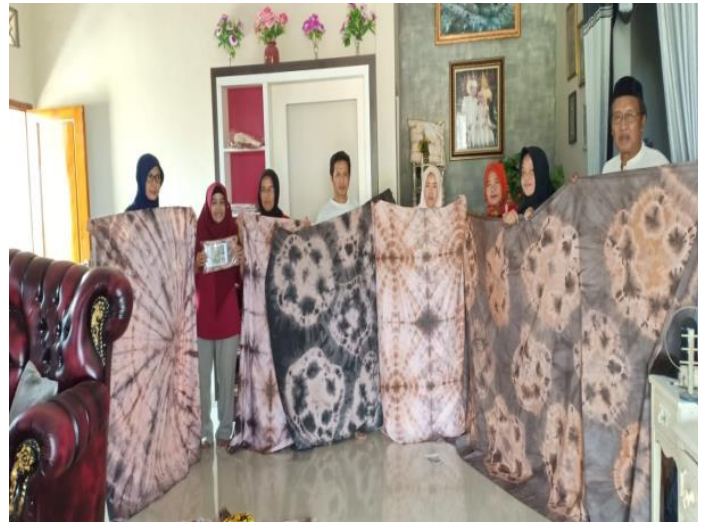

Foto Bareng Wakil Bupati Gresik

Acara Lomba Wisata Tangguh

Tanggal 08 Juli 2020

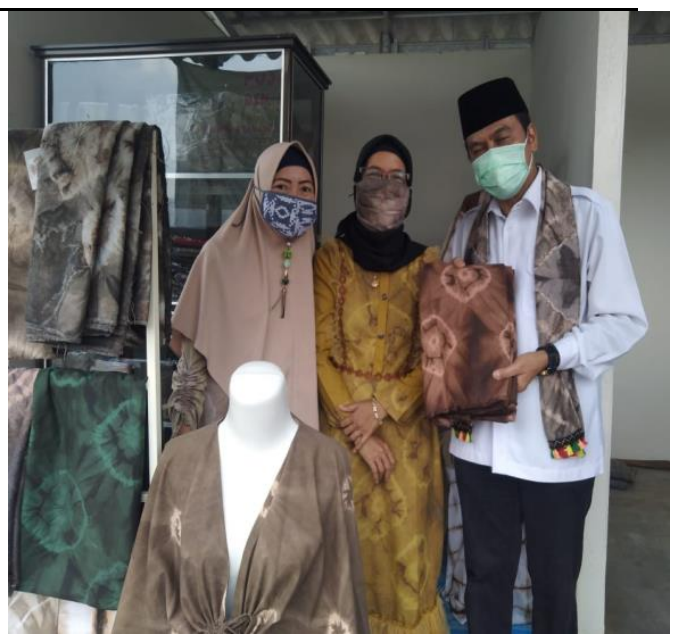

Sebelum mendapatkan Pelatihan Varian Produk batik, Mitra Assalam RYY ini Produk terbatas. Setelah mengikuti pelatihan varian produk batik yang dihasilkan menjadi semakin bervariasi, yaitu Syaal,Sapu tangan,Tas

perempuan,,Masker,auter,baju,mukena, Jilbab, kain batik dll.

Sebelum mendapatkan Pelatihan pemasaran mitra Assalam ini hanya memasarkan produknya secara getok tular (dari mulut ke mulut). Hasil penjualannya masih kurang, setelah mengikuti Pelatihan melalui olshop di era pandemi ini (Whatsapp, LINE, Instagram ) hasil penjualannya lebih besar.Pada era pandemi ini harus ber upaya bagaimana cara untuk menjemput bola dalam hal pemasaran dan Allahamdulilah bisa eksis di era pandemi ini.

Sebelum mendapatkan pelatihan untuk pembukuan sederhana, pencatatan keuangan Ekonomi, Sosial, dan Budaya 
masih belum tertib,masih camur keuangan antara pemasukan dan pengeluaran. Setelah mendapatkan pelatihan pembukuan sederhana, pencatatan keuangan menjadi lebih tertib,dan kelihatan lebih praktis.

Dengan dilaksanakannya teknik pendampingan (monitoring dan evaluasi), permasalahan- permasalahan yang timbul segera didiskusikan untuk penyelesaian masalahnya.

Hasil produksi Batik Assalam

PRODUK SEBELUM PELATIHAN

*Kain batik

*Penjualan per bulan 1-4 kain

*Harga jual perkain Rp.200.000

Rata - rata hasil perbulan 3 kain

Rp. 600.000

Varian produk batik setelah pelatihan

1. Syaal

2. Jilbab

3.Baju

4.Auter

5.Masker

6.Sapu tangan

7. Kain Batik dengan beberapa desain

Hasil Varian Batik Assalam

\begin{tabular}{|l|l|c|}
\hline \multicolumn{1}{|c|}{$\begin{array}{c}\text { Hasil } \\
\text { Produksi }\end{array}$} & $\begin{array}{c}\text { Sebelum } \\
\text { Pelatihan }\end{array}$ & $\begin{array}{c}\text { Sesudah } \\
\text { Pelatihan }\end{array}$ \\
\hline 1. Syaal & Tidak ada & 15 \\
\hline
\end{tabular}

\begin{tabular}{|c|c|c|}
\hline & & $\begin{array}{l}\text { Harga } \\
\text { Rp.50.000 } \\
\text { Omzet perbln } \\
\text { Rp.750.000 }\end{array}$ \\
\hline 2. Jilbab & Tidak ada & $\begin{array}{l}20 \\
\text { Harga } \\
\text { Rp.40.000 } \\
\text { Omzet } \\
\text { perbulan Rp } \\
800.000\end{array}$ \\
\hline 3. Mukenah & Tidak ada & $\begin{array}{l}6 \\
\text { Harga } \\
\text { Rp.300.000 } \\
\text { Omzet } \\
\text { perbulan Rp } \\
1.800 .000\end{array}$ \\
\hline 4. Baju & Tidak ada & $\begin{array}{l}4 \\
\text { Harga } \\
150.000 \\
\text { Omzet perbln } \\
\text { Rp. } 600.000\end{array}$ \\
\hline 5. Auter & Tidak ada & $\begin{array}{l}3 \\
\text { Harga } \\
180.000 \\
\text { Omzet } \\
\text { perbulan Rp } \\
720.000\end{array}$ \\
\hline 6. Masker & Tidak ada & $\begin{array}{l}100 \\
\text { Harga rp } \\
5.000 \\
\text { Omzet perbln }\end{array}$ \\
\hline
\end{tabular}

Ekonomi, Sosial, dan Budaya 


\begin{tabular}{|c|c|c|}
\hline & & Rp 500.000 \\
\hline $\begin{array}{l}7 . \quad \text { Sapu } \\
\text { Tangan }\end{array}$ & Tidak ada & $\begin{array}{l}20 \\
\text { Harga rp } \\
7.000 \\
\text { Omzet perbln } \\
\text { Rp140.000 }\end{array}$ \\
\hline $\begin{array}{l}8 . \quad \text { Tas } \\
\text { Perempuan }\end{array}$ & Tidak ada & $\begin{array}{l}6 \\
\text { Harga } 35.000 \\
\text { Omzet perbln } \\
\text { Rp210.000 }\end{array}$ \\
\hline $\begin{array}{l}\text { 9. Kain Batik } \\
\text { dengan }\end{array}$ & Ada & $\begin{array}{l}10 \\
\text { Harga Rp } \\
300.000 \\
\text { Omzet perbln } \\
3.000 .000\end{array}$ \\
\hline
\end{tabular}

\section{KESIMPULAN DAN SARAN}

Pengabdian Masyarakat ini menunjukkan realita pengembangan masyarakat sebagai suatu proses bergerak dari satu tahap ke tahap berikutnya, sebuah metode untuk menciptakan tujuan, sebuah prosedur program sebagai sebuah gerakan. Di era pandemi ini nampak pada rasa percaya diri, rasa bangga, semangat, dan gairah kerja agar tetap mendapatkan penghasilan, sehinngga tercipta peningkatan kesejahteraan masyarakat.

Saran untuk mitra : 1) Mempertahankan standart kualitas batik yang disukai pembeli
2) Meningkatkan pengembangan sumber daya manusia dalam bidang IT, khususnya pengembangan produk dan marketing. 3) Meningkatkan kreasi varian produk batik dengan memperhatikan pasar yang ada serta jangka panjang.

\section{DAFTAR PUSTAKA}

\section{Buku :}

Sairin, Sjafri, 2002, Perubahan Sosial Masyarakat Indonesia : Perspektif Antropologi, Pustaka Pelajar, Yogyakarta.

Soemarwoto Otto, 1997, Ekologi Lingkungan Hidup Dan Pembangunan, edisi revisi, Jambatan, Jakarta

\section{Website :}

https://translate.google.co.id/\#fr/id/ $\underline{\text { souvenir }}$ www.mikirbae.com/2015/03/membuatbatik- ikat- celup.html http://id.search.yahoo.com http.www.indokabana.com/motif/sejarahkain-ikat-di-indonesia-lengkap

\section{Jurnal}

Alamsyah,2018.Kerajinan Batik dan pewarnaan Alami.Jurnal Endogami; Jurnal Ilmiah Kajian Antropologi,EISSN: 2599-1078

Mahendra 2016.Peningkatan desain dan ketrampilan Batik Celup ikat untuk meningkatkan Minat Wira Usaha 
Masyarakat.Jurnal,Desain Interior,Vol 1 No.1 April 2016 ISSN 2527-2853

Pujilestari,Titiek.2014.Pengaruh

Ekstraksi Zat Warna Alam dan diksasi Terhadap ketahanan Luntur warna pada kain batik katun (The Effect Extraction Method And Fixation Of Natural Dyes to Color Fastness on cotion fabric).Jurnal Dinamika kerajinan dan Batik,Vol 31 no. 1 Juni 2014,hlm 2

Satriya,Yudi dan Dwi Suheryanto.2016.Pengaruh Temperatur Ekstraksi Zat Warna Alam Daun Jati terhadap kulaitas dan Arah Warna Batik (The effect of Natural Dyes Teak Leades Extraction Temperature to the Quality and Color Direction in Batik).Jurnal Dinamika kerajinan dan Batik Vol 33 no 2 Tahun 2016,hlm 101-102 dalam https;//media.nelti.com/publications/5953 8-ID-Pengaruh temperatur ekstraksi zat warna.pdf 
Prosiding PKM-CSR, Vol. 3 (2020)

e-ISSN : 2655-3570

Ekonomi, Sosial, dan Budaya 